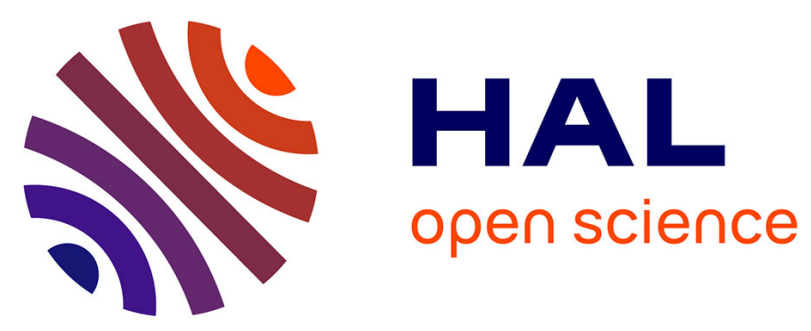

\title{
Interfacial damage in biopolymer composites reinforcedusing hemp fibres: Finite Element simulation and experimental investigation
}

\author{
M. Hbib, S. Guessasma, David Bassir, N. Benseddiq
}

\section{- To cite this version:}

M. Hbib, S. Guessasma, David Bassir, N. Benseddiq. Interfacial damage in biopolymer composites reinforcedusing hemp fibres: Finite Element simulation and experimental investigation. Composites Science and Technology, 2011, 71 (11), pp.1419. 10.1016/j.compscitech.2011.05.015 . hal-00773221

\author{
HAL Id: hal-00773221 \\ https://hal.science/hal-00773221
}

Submitted on 12 Jan 2013

HAL is a multi-disciplinary open access archive for the deposit and dissemination of scientific research documents, whether they are published or not. The documents may come from teaching and research institutions in France or abroad, or from public or private research centers.
L'archive ouverte pluridisciplinaire HAL, est destinée au dépôt et à la diffusion de documents scientifiques de niveau recherche, publiés ou non, émanant des établissements d'enseignement et de recherche français ou étrangers, des laboratoires publics ou privés. 


\section{Accepted Manuscript}

Interfacial damage in biopolymer composites reinforcedusing hemp fibres: Finite Element simulation and experimental investigation

M. Hbib, S. Guessasma, D. Bassir, N. Benseddiq

PII: S0266-3538(11)00189-8

DOI: 10.1016/j.compscitech.2011.05.015

Reference: CSTE 4995

To appear in: Composites Science and Technology

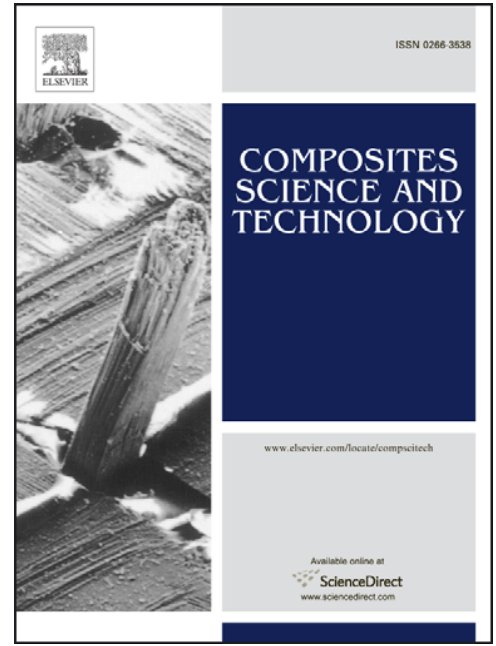

Received Date: $\quad 14$ February 2011

Revised Date: $\quad 13$ May 2011

Accepted Date: $\quad 22$ May 2011

Please cite this article as: Hbib, M., Guessasma, S., Bassir, D., Benseddiq, N., Interfacial damage in biopolymer composites reinforcedusing hemp fibres: Finite Element simulation and experimental investigation, Composites Science and Technology (2011), doi: 10.1016/j.compscitech.2011.05.015

This is a PDF file of an unedited manuscript that has been accepted for publication. As a service to our customers we are providing this early version of the manuscript. The manuscript will undergo copyediting, typesetting, and review of the resulting proof before it is published in its final form. Please note that during the production process errors may be discovered which could affect the content, and all legal disclaimers that apply to the journal pertain. 


\section{Interfacial damage in biopolymer composites reinforced using hemp fibres:}

\section{Finite Element simulation and experimental investigation}

M. Hbib ${ }^{1}$, S. Guessasma*1, D. Bassir ${ }^{2}$, N. Benseddiq ${ }^{3}$

${ }^{1}$ INRA, UR1268 Unité Biopolymères Interactions et Assemblage (BIA), Rue de la

Géraudière, F-44000 Nantes, France

${ }^{2}$ Departement of Mechanical Engineering, University of Technology of Belfort-Montbéliard, 90000 Belfort, France

${ }^{3}$ University of Science and Technology of Lille, IUT-A GMP, BP179

59653 Villeneuve d'Ascq, France

* corresponding author

sofiane.guessasma@nantes.inra.fr, tel. +33 240675036 , fax. +3324067 5167

\section{Abstract}

The present study aims at considering the effect of interfacial damage on the mechanical performance of a starchy composite reinforced using hemp fibres. Mechanical behaviour is approached experimentally using tensile testing coupled to digital image acquisition.

Thermomoulded samples with single fibres are designed to allow sample testing perpendicularly to the direction of fibre alignment. Experimental evidence of localised damage is then highlighted in the elasticity stage. Finite Element computation is attempted to explain the observed damage using an adequate mechanical model that considers weak adhesion between phases and dynamic evolution of damage. Predicted results show that the FE model is able to reproduce the observed behaviour suggesting that local damage evolution is a serious mechanism affecting the performance of the studied composite.

\section{Keywords}

A. Fibres B. Debonding, B. Interface C. Damage mechanics C. Finite element analysis (FEA). 


\section{Brief history about mechanical performance of fibre-based composites}

The use of natural fibres as reinforcements in structural composites has gained considerable attention these last years [1-3]. Over 4100 published papers have been reported within the period 1975 -2009 on flax and about 1600 works on hemp within the same period. Such attention is justified by specific strength comparable to synthetic fillers, low cost and biodegradability. In the counter part, design of structural materials using natural fibres rises several drawbacks such as limited fibre length, varied quality and degradation of the physical characteristics at high operating temperatures [4].

A precise control of the fabrication process is determinant to obtain composites with efficient mechanical performance [5]. There is still considerable effort in this regard and a great deal of innovation to come up. For instance, the control of processing conditions and preprocessing steps during moulding can lead to a substantial reduction of fibre damage [6-8]. Physical or chemical treatments of natural fibres are also matters of concern since good adhesion properties can be achieved $[7,9,10]$. Some studies tend to indicate that minor or secondary improvement are rather obtained by uniquely improving interfacial properties [5].

Consequently, the increase in fibre content maybe privileged to compete with synthetic materials such as glass fibres.

Bodros and co-workers [6] studied different thermoplastics reinforced by flax fibres. They obtained elastic moduli in the range 2-10 GPa, tensile strengths varying between 20 and 100 MPa and strain at rupture between $1-2.5 \%$ for a fibre content varying between 20 and $40 \%$. Concerning hemp fibres, Ruisson and co-workers [1] studied hemp reinforcing effect on a polyester matrix (tensile strength $13 \mathrm{MPa}$, Young's modulus 1.1 GPa).

The authors measured tensile strengths and moduli in the ranges $(20-60) \mathrm{MPa}$ and (1.2 1.7) GPa, respectively. With a polystyrene matrix and both treated and untreated hemp strands (content of about 22\%), yield stress and strain were found lying between 40 and $43 \mathrm{MPa}, 1.9$ 
and $2.2 \%$, respectively. An elastic modulus as high as $4.9 \mathrm{GPa}$ and tensile strength of about $47 \mathrm{MPa}$ have been achieved with $40 \%$ of hemp content reinforcing a polypropylene matrix [7]. In a companion work, $\mathrm{Li}$ and Pickering [9] found tensile strengths ranging from 22 to 42 $\mathrm{MPa}$, depending on hemp treatment. Keller [11] measured the effect of degummed hemp fibre on the mechanical properties of degradable materials containing either brittle or ductile matrices. While the effect of the matrix was most important, significant improvement of the mechanical parameters were observed for hemp fractions as large as $27 \%$. The impact strength and the elongation at break decreased from 25 down to $5 \mathrm{Kj} / \mathrm{m}^{2}$ and from 8 down to $0.89 \%$. The largest modulus and tensile strength were $3.5 \mathrm{GPa}$ and $30 \mathrm{MPa}$, respectively. The above review demonstrates the wide scatter on the reported properties. At the light of the examined data, biocomposites reinforced using hemp fibres are upper bounded as follows Young's modulus $<5 \mathrm{GPa}$, tensile strength $<50 \mathrm{MPa}$, Some of their properties are lower bounded such as impact strength $>5 \mathrm{Kj} / \mathrm{m}^{2}$ and elongation at break $>0.8 \%$.

As a raw material, hemp possesses interesting specific mechanical properties compared to glass fibres [3]. Pickering and co-workers [7, 9] report tensile strength of single hemp fibres between 500 and 850 MPa. Cheung and co-workers [12] report a broad windowing of hemp fibre properties: elastic modulus (30 - $70 \mathrm{GPa})$, elongation at break (1.6-6)\% and tensile strength 310 to $390 \mathrm{MPa}$.

Non-destructive techniques such as acoustic emission are used to derive information about microfailure mechanisms and fracture strength in presence of either matrix or interfacial damage [13-15].

Several studies conclude that the understanding fibre treatment effect on the overall composite properties require adequate experiments to determine the matrix/fibre adhesion properties [8]. In this paper, simple tensile experiments are combined with an adequate finite element model to derive such an information. Moreover, interfacial damage is suggested and 
quantified to explain failure mechanisms and the reduction of the mechanical performance of the studied biocomposite.

In this regard and among the analytical and numerical approaches that have been considered to study interfacial damage $[16,17]$, Finite element computation has gained much importance these last decades [18]. Voyiadjis and Park studied matrix, fibre and interfacial damages in ductile composites and developed accordingly a micromechanical model based on the effective stress concept [19].

It is commonly admitted to define interfacial damage by means of a non-dimensional variables such that $[20]$

$\mathrm{D}=\frac{1_{0}-1}{1_{0}}$

where $l_{0}$ is the total length of the interface, 1 is the undamaged or resistant interface length. D goes from 1 down to 0 .

The definition given in equation (1) has a more general validity and thus can be adopted for other structural damages such as microcavities, voids and microcracks. See [21] for a deeper discussion.

Damage can be implicitly implemented in the constitutive laws by modifying, for example, the elastic tensor such that [22]

$$
\begin{aligned}
& S_{i i}^{*}=\frac{1}{C_{i i}\left(1-D_{i i}\right)} \\
& S_{i j i \neq j}^{*}=\frac{v_{i j} D_{i j}}{C_{i i}\left(1-D_{i i}\right)}
\end{aligned}
$$

where $S_{\mathrm{ij}}^{*}$ is the overall compliance tensor that accounts for damage, $\mathrm{C}_{\mathrm{ij}}$ is the elastic tensor of associated to the undamaged material, $v_{\mathrm{ij}}$ is Poisson coefficient.

In several finite element studies, interfacial damage is accounted using interface elements with either spring like or cohesive zone models [16, 17, 23, 24]. Cohesive models allow a 
more progressive damage evolution. Similar results can be obtained using spring-like models at the cost of considering continuous decrease of the interface compliance. In our case, the interface properties are zeroed to simulate a more aggressive damage evolution. In this regard, the model is simpler since it does not require a constitutive law describing the evolution rate of damaged interfaces.

In our study, hemp fibres are considered as homogeneous and isotropic materials despite that the real material contains highly contrasted phases. Such a limitation is widely assumed in the literature [22] because, in most cases, the highlighted matter is interfacial debonding.

\section{Experimental layout}

Thermomoulding of starch with aligned hemp fibres is considered for the study of the damage evolution. The reinforcement material is natural hemp fibres provided by Institut du Chanvre (ITC - Troyes, France). Optical microscopy reveals a well separated hemp strands exhibiting a large dispersion in the fibre diameters (Figure 1a). Despite this large dispersion, it is still possible to have an estimation of the fibre diameter using SEM observation (Figure 1b). As we do not deal with short fibres rather than long ones, the main shape characteristic of the hemp fibre is its smallest dimension since infinite shape factor is effective in our case. Simple image analysis reveals bundle average size of about $300 \mu \mathrm{m}$ and smallest fibres have typical dimension of $20 \mu \mathrm{m}$. In addition, SEM micrograph reveals the defected surface of the hemp fibre, which, in most cases, can be responsible for adhesion problems. The preprocessing procedure carried out in this study to obtain an amourphous matrix is identical to that published in several papers of the group. See for example [25]. Native potato starch (initial water content is $13 \%$ ) is extruded using a single screw extruder. Cryogrinding is then performed to mechanically transform the extrudates into a powder. The resultant powder is stored in a controlled environment before further processing. In particular, amorphous starch without glycerol requires at least two weeks to achieve a final water content of about $13 \%$ 
under a relative humidity of $59 \%(\mathrm{NaBr})$ and at a temperature of $20^{\circ} \mathrm{C}$. Thermomoulding is then undertaken using isolated hemp fibres carefully positioned perpendicularly to the largest dimension of the mould. Sample processing includes a moulding pressure of about $43 \mathrm{MPa}$, heat treatment based on a regular increase of temperature from $20^{\circ}$ up to $120^{\circ} \mathrm{C}$ for about 5 minutes. A plateau temperature is maintained for 10 minutes before water cooling of the mould which brings back sample temperature to $20^{\circ} \mathrm{C}$ in less than 15 minutes. Samples of about $35 \times 10 \times 1 \mathrm{~mm}$ in dimensions are obtained and stored under the same conditions as mentioned above.

Mechanical testing is realised using a micromechanical equipment allowing microdisplacement control with an accuracy of about $1.25 \mu \mathrm{m}$. All experiments are conducted under a constant displacement rate of $40 \mu \mathrm{m} . \mathrm{s}^{-1}$ up to failure or when the force reaches the peak force of the load cell $(125 \mathrm{~N})$. In addition, testing is coupled to optical microscopy observation using a stereomicroscope (Figure 1b). The frame rate is fixed to $100 \mathrm{fps}$ whereas the ROI area is adjusted to about $460 \times 400$ pixels. Each pixel has a physical dimension of about $25 \mu \mathrm{m}$. Four samples per processing conditions are considered and the mechanical response is derived in each case by examining the stress-strain relationship.

\section{Modelling technique}

Dynamic simulation of damage evolution in starchy composite is considered following two main steps: sensitivity analysis and identification. Within the first step, a micromechanical model is developed to simulate the mechanical response of the composite reinforced using a single fibre. The model is augmented by the implementing varied adhesion properties between constituents. In addition, damage evolution is followed where all possible structural and mechanical effects are considered such as the strength of the interfacial adhesion and the fibre orientation. Such analysis provides a framework for the study of damageable composites and has a numerical validity beyond the specific case of hemp/starch composite. 
The second step aims at considering the adequate adjustment of the model parameters in order to fit the specific case of starch/hemp under the same loading and geometric constraints. This step is performed by manual change of the parameters by selecting adequate windowing of the involved parameters.

In a 2D grid of typical dimensions (128x128) pixels, a centred fibre is generated of infinite length and a fixed diameter W. The intersect between the largest dimension of the fibre and the horizontal axis defines the fibre angle $(\theta)$. The physical dimension of the grid is fixed to $10 \mathrm{~mm}$, according the experimental setup. The pixel size is thus $78 \mu \mathrm{m}$.

The grid is converted into a finite element mesh using plane elements capable of translations in the 2D space directions $\mathrm{X}$ and $\mathrm{Y}$ (Figure 2). ANSYS software is used for such a purpose. Each element (plane42 using ANSYS nomenclature) is defined by four nodes. Both matrix and fibre are meshed using the same plane element. In addition, 1D interface elements (combin14 using ANSYS nomenclature) are implemented when a switch between phases is detected. The implementation procedure is similar to the process described in [26]. Elastic and isotropic material properties are implemented for each phase:

$$
\sigma_{(\mathrm{i})}=\frac{\mathrm{E}_{(\mathrm{i})}}{\left(1+\mathrm{v}_{(\mathrm{i})}\right)}\left(\varepsilon_{(\mathrm{i})}+\frac{v_{(\mathrm{i})}}{1-2 v_{(\mathrm{i})}} \mathrm{I}_{\varepsilon}\right) \quad \mid \mathrm{i} \in\{\mathrm{M}, \mathrm{F}\}
$$

where

$\sigma$ and $\varepsilon$ are stress and strain tensors, $E$ and $v$ are engineering constants for an isotropic material. The numbering holds for the two phases of the composite.

All computations are conducted assuming plane stress state. If elastic properties are not explicitly indicated for both phases, Young's modulus and Poisson coefficient are $\mathrm{E}_{\mathrm{M}}=2.62$ $\mathrm{GPa}, \mathrm{v}_{\mathrm{M}}=0.3, \mathrm{E}_{\mathrm{F}}=20 \mathrm{GPa}$ and $\mathrm{v}_{\mathrm{F}}=0.3$, for the matrix and filler, respectively.

Starch-hemp fibre is considered as imperfect, which means that normal and shear displacement jumps do exist at the interface together with traction continuity. The other 
hypothesis is linearly between interfacial tractions and displacements in both normal and sliding directions. The tractions exerted at the interface take the following forms $t_{i}^{(1)}=s_{i j}^{(1)}\left(-n_{j}\right)$

$t_{i}^{(2)}=s_{i j}^{(2)} n_{j}$

where

$t_{i}^{(I)}=t_{i}^{(2)}=-t_{i}^{(1)}$

and

$t_{i}^{(1)}, t_{i}^{(2)}$ are the traction exerted from the matrix to the inclusion and vice versa. $n_{j}$ is the normal direction to the interface.

From the former postulate, traction can write as function of displacement jumps:

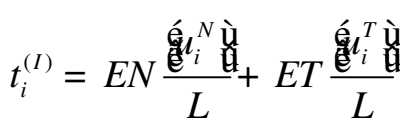

where

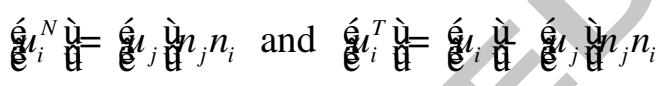

and

EN and ET are normal and tangential stiffness parameters associated to the interface,

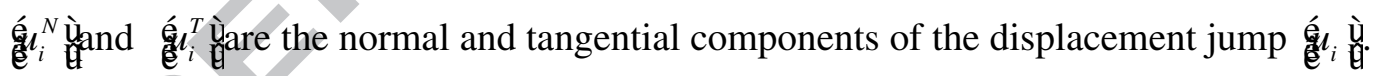

EN and ET are varied in a wide range to account for weak and strong interface properties.

Note that when both parameters are zeroed, compliance of the interface layer becomes infinite, which corresponds to the case of complete debonding (see for example [16] and references cited there). If the interface parameter values are infinite, perfect bonding is obtained. 
Damage is implemented by considering abrupt degradation of interface elements following the work of Benabou and co-workers [23]. Based on this work, interface elements are deactivated when a suitable linear combination of normal traction (FN) and shear force (FT) exceeds the interfacial strength $(\mathrm{R})$

$\mathrm{FN}+\beta \mathrm{FT} \geq \mathrm{R}$

where $\beta$ is a constant that modulates the contribution of shearing force.

We use stress units more convenient knowing that, for a regular meshing, interface units are of same dimensions whereas in [23] where irregular meshing is used, switching between pressure and force units involves a more complex math.

Damage variable $\delta$ is monitored to compute, for any strain value, the ratio of deactivated elements with regards to the total number of interface elements.

Loading conditions correspond to the case of a uniaxial traction. We conform the loading conditions to the fact that samples are glued on the fixtures as follows

$$
\begin{gathered}
\mathrm{Ux}=\mathrm{U} / 2 \\
\mathrm{Uy}=0
\end{gathered} \mid \mathrm{x}=\mathrm{L}
$$

and

$$
\begin{gathered}
\mathrm{Ux}=-\mathrm{U} / 2 \\
\mathrm{Uy}=0
\end{gathered}
$$

where $\mathrm{L}$ is the sample length.

\section{Results and discussion}

\subsection{Evidence of damage growth}

Figure 3 shows an image sequence illustrating the interfacial damage growth in starch/hemp composite. The bundle size is about $940 \mu \mathrm{m}$. Up to a strain of $0.4 \%$, microstructure evolution does not seem to show any microfailure mode or if so it is undetectable at the surface of the 
sample. Figure $3 \mathrm{~b}$ shows a small arrowed dark region within the interface indicating localisation and onset of the interfacial damage. At such a strain, the load transfer between the matrix and the fibre becomes altered by the creation and the growth of microvoids (see Figure $3 \mathrm{c}$ and $3 \mathrm{~d}$ ). The interfacial damage mechanism lowers the overall stress level as attested by the stress non-uniformity (stress-strain curve not shown). At the peak stress, the damage percolates in the full dimension leading to an abrupt rupture (Figure 3e). The ground stress value at rupture indicates that the matrix/fibre frictional forces are not sufficient to allow a positive drop in the stress [27].

Figure $3 e$ provides qualitative information about material failure mechanism. Considerable stress reduction is induced by the formation of microvoid initiation and growth. There are stress concentrators that enhance radial (i.e., normal to the loading direction) cracking because of the tensile hoop stress acting on the interface [14]. Thus, fracture develops perpendicularly to the loading direction in a way similar to the fracture opening mode.

\subsection{Sensitivity analysis on interfacial damage evolution}

The objective of this section is to provide quantitative predictions about the main influential factors affecting interfacial damage evolution.

Figure $4 \mathrm{a}$ compares the present model to the result of the two-phase model, which assumes continuity of both traction and displacement across the interface. Also is shown in the same figure the prediction related to the weak-interface model. In this model, the interface acts against the load transfer by a finite and low stiffness compared to the properties of the two phases forming the composite. Under these conditions, the elastic modulus of the composite is substantially decreased because of the presence of weak interface (EN/EM=0.04,EN=ET). Imperfect interface reduces the filler/matrix load transfer which, in turn, lowers the stress level. For a deeper discussion of imperfect interface effect using the spring-like interaction, the reader is refereed to [26]. When damage criteria are implemented, significant stress drop 
is predicted (Figure 4a). The monitoring of the damage variable shows that the strain level at which the stress drop is observed corresponds exactly to the beginning of interfacial damage. The value of the computed damage variable $(\delta)$ increases within a deformation range of about $0.1 \%$. At the imposed displacement, $\delta$ does not exceed $50 \%$ which means that a significant amount of undamaged interfaces still remains. The analysis of the principal stress evolution allows the determination of the spatial distribution of the damaged interfaces (Figure 4b). Considerable stress reduction is predicted for $\varepsilon>0.88 \%$ because of interfacial damage which develops starting from the sample edge along the fibre/matrix interfaces. The observed fractured sample shows similar trend.

Figure 5 illustrates the effect of varying the geometrical features on the mechanical response of the starch-fibre composite. Behind changing the fibre width, there is a variation of the fibre fraction, and in turn a change in the slope of the stress-strain relationship as demonstrated in Figure 5a. Simple rational allows the determination of the composite Young's modulus assuming mixture laws available for two-phase materials [28]

$$
E=\frac{E_{F} E_{M}}{\frac{W}{L}\left(E_{M}-E_{F}\right)+E_{F}}
$$

where $\mathrm{E}, \mathrm{E}_{\mathrm{F}}, \mathrm{E}_{\mathrm{M}}$ are elastic moduli of the composite, filler and matrix, respectively. $\mathrm{W}$ is the fibre width and $L$ is the sample dimension.

The increase in stiffness makes it possible to reach higher stress values for the same imposed strain. In that way, damage occurs and develops earlier as a consequence of the load transfer. In Figure $5 b$ is shown the effect of fibre orientation on the damage evolution. Fibre orientation plays an important role on changing the balance between normal and tangential components of the interfacial resistance. Indeed, when the fibre is parallel to the loading direction, the interface is exposed to shearing whereas the same interface experiences traction 
when the fibre is normal to the loading direction. For an intermediate orientation, the interfacial force combines both normal and tangential forces. The predictions show that the final magnitude of the damage variable is low when $\theta$ decreases. According to equation (10) and knowing that $\beta=0.5$, damage growth is limited as the fibre angle decreases. Angles below $90^{\circ}$ cause a more progressive damage which affect nonlinearly the stress- strain relationship. In particular, stiffness reduction is predicted by the creation of micro-voids. This result contrasts with $\theta=90^{\circ}$ since, in this case, severe stress reduction caused by the fast damage growth clearly leads to material rupture.

Figure 6 displays the effect of damage criteria on the mechanical response and damage growth. The change in the interfacial resistance has nothing to deal with the slope of the stress - strain curve rather than to be sensitive to the stress value. A small $\mathrm{R}$ value is then correlated to an earlier starting of damage (Figure 6a). If failure is uniquely governed by interfacial damage, then $\delta$ is simply correlated to the strength of the material. Figure 6a illustrates the effect of the balance between shear and traction effects through the consideration of various values of coefficient $\beta$ in equation (10). A large $\beta$ value makes damage criterion more sensitive to shearing but also it shifts $\mathrm{R}$ to higher levels. It is shown here that earlier damage development occurs when $\beta$ takes large values as a consequence of a more involved shearing effect in the damage process. It seems that damage is positively correlated to the ratio $\mathrm{R} / \beta$. This quantity is related to the ultimate properties (strain and stress at break) as shown Figure $6 \mathrm{~b}$ by considering different combinations. It is clearly demonstrated that a linear correlation do exist between both ultimate parameters and the damage criteria ratio $\mathrm{R} / \beta$. $\sigma_{f}(M P a)=0.51+0.68 R / \beta(M P a) \quad ; \mathrm{R}^{2}=0.97 \quad(14)$ and 
$\varepsilon_{f}(\%)=0.218+0.280 R / \beta(M P a) \quad ; \mathrm{R}^{2}=0.97$

This result suggests that interfacial damage controls linearly rupture properties under elasticity conditions.

Figure $6 \mathrm{c}$ shows the effect of varying interface properties combining both interfacial shearing and traction stiffness. When both parameters are equally considered (EN=ET), the increase of interfacial stiffness improves the overall stiffness of the composite as long as $\mathrm{EN}<\mathrm{E}_{\mathrm{F}}$, where $\mathrm{E}_{\mathrm{F}}$ refers to Young's modulus of the fibre. Passing this limit, the stress-strain slope is not much affected. This has a direct consequence on damage evolution as shown in Figure 6c. Considering damage criterion to be drastic, weak interface conditions would normally lead to low interfacial stress, which delays damage onset. Indeed, failure strain reaches 0.024 when $\mathrm{EN}=\mathrm{ET}=0.04$ whereas it is below 0.013 for $\mathrm{EN}=4.33$.

The normal stiffness seems to be the key factor affecting more damage evolution. Following the idea that EN controls better uniaxial deformation, especially when the loading direction is perpendicular to the interface plane [26], a large EN value increases the stress-strain slope and by the way higher stress levels are quickly reached at the interface. As shown in Figure 6c, when ET>EN, the composite stiffness is not increased and remains similar to the case $\mathrm{EN}=\mathrm{ET}=0.04$. However, damage occurs earlier in the former case because of the large interfacial shearing force. We should mention then that change in interfacial tangential stiffness provides a way to predict if the damage criterion is more or less sensitive to shearing effects.

The identification of the mechanical behaviour of starchy composite reinforced using hemp fibres is undertaken by tuning each of the damage related parameters. Instead of considering an automated way for parameter search like in [29], manual adjustment of parameters is rather used. Figure 7 illustrates the principal of optimal parameter determination. Assuming that the 
filler/matrix elastic moduli ratio is 7.63 , interfacial stiffness parameters are adjusted based on optimal fitting of the stress-strain slope (Figure 7). We also use the constraint EN=ET, which means that interfacial properties are assumed to be rather isotropic. In Figure 7a, normal interface stiffness is first adjusted using an excessive interfacial strength $(\mathrm{R} / \beta=2.560 \mathrm{GPa})$. The best matching is obtained for $\mathrm{EN} / \mathrm{E}_{\mathrm{M}}=0.25 \%$, where $\mathrm{E}_{\mathrm{M}}$ refers to starch modulus. Giving this optimal value, $R / \beta$ is adjusted to fit the stress at rupture. Figure 7 a shows that the best matching is obtained for $\mathrm{R} / \beta=13.89 \pm 0.01 \mathrm{MPa}$. The identification procedure is repeated for four other samples, where each identification scheme requires up to $84 \mathrm{FE}$ runs, each run consumes $1 / 2$ hour on a quad-core Intel®Xeon processor. The numerical results predict a fair linear correlation between interfacial strength and interface stiffness (Figure 7b) $R / \beta(M P a)=-2.43+6593 E N / E S(\%) \quad ; \mathrm{R}^{2}=0.99 \quad(16)$ where $E N / E S(-) \geq 3.69 \times 10^{-4}$ holds for the physical constraint in equation (16). Note that this result suggest that, under elasticity deformation, ultimate properties are related to the interfacial stiffness parameters if the damage mechanism is identified. This can obtained simply by substituting R/b by one of the expressions in equations (14) and (15).

\section{Conclusions}

Evidence of interfacial damage in starch-hemp composite is pointed out experimentally, which justifies the study of ultimate properties with regard to interfacial damage. Damage growth is sensitive to several parameters:

- Interfacial strength weighted by the inverse of shearing constant is predicted to be linearly correlated to the overall failure properties;

- Phase ratio as well as interfacial stiffness parameters are accounted as tuning the damage onset if all other variables are kept constant including damage criterion related parameters. In such a way, tangential stiffness affects the critical shearing force without much influencing 
the overall composite stiffness. Normal stiffness affects the composite stiffness and, by the way, the interfacial force including both shearing and tension components;

- Fibre orientation affects the stress-strain relation and controls the an unbalance between shearing and tension effects at the interface;

- The identification of the damage behaviour of the starchy composite reveals a linear correlation between the interfacial stiffness parameters and the damage criterion. This result suggests that improvement of interfacial properties allows a better control of damage onset.

\section{References}

[1] Roulson D, Sain M, Couturier M. Resin transfer molding of hemp fiber composites: optimization of the process and mechanical properties of the materials. Composites Science and Technology 2006;66:895.

[2] Hepworth DG, Bruce DM, Vincent JFV, Jeronimidis G. The manufacture and mechanical testing of thermosetting natural fibre composites. J. Mater. Sci. 2000;35:293.

[3] Saheb D, Jog J. Natural fiber polymer composites: A review. Advances in Polymer Technology 1999;18:351.

[4] Herrmann AS, Nickel J, Riedel U. Construction materials based upon biologically renewable resources - from components to finished parts. Polymer Degradation and Stability 1998;59:251.

[5] Vilaseca F, Lopez A, Llauro X, Pelach MA, Mutje P. Hemp strands as reinforcement of polystyrene composites. Chemical Engineering Research \& Design 2004;82:1425.

[6] Bodros E, Pillin I, Montrelay N, Baley C. Could biopolymers reinforced by randomly scattered flax fibre be used in structural applications? Composites Science and Technology 2007;67:462.

[7] Pickering KL, Beckermann GW, Alam SN, Foreman NJ. Optimising industrial hemp fibre for composites. Composites Part a-Applied Science and Manufacturing 2007;38:461.

[8] Stuart T, Liu Q, Hughes M, McCall RD, Sharma HSS, Norton A. Structural biocomposites from flax - Part I: Effect of bio-technical fibre modification on composite properties. Composites Part a-Applied Science and Manufacturing 2006;37:393.

[9] Li Y, Pickering KL. Hemp fibre reinforced composites using chelator and enzyme treatments. Composites Science and Technology 2008;68:3293.

[10] Pracella M, Chionna D, Anguillesi I, Kulinski Z, Piorkowska E. Functionalization, compatibilization and properties of polypropylene composites with Hemp fibres. Composites Science and Technology 2006;66:2218.

[11] Keller A. Compounding and mechanical properties of biodegradable hemp fibre composites. Composites Science and Technology 2003;63:1307.

[12] Cheung HY, Ho MP, Lau KT, Cardona F, Hui D. Natural fibre-reinforced composites for bioengineering and environmental engineering applications. Composites Part BEngineering 2009;40:655.

[13] Park JM, Kim DS, Kim SR. Improvement of interfacial adhesion and nondestructive damage evaluation for plasma-treated PBO and Kevlar fibers/epoxy composites using 
micromechanical techniques and surface wettability (vol 264, pg 431, 2003). Journal of Colloid and Interface Science 2003;268:271.

[14] Shaw LL, Karpur P, Matikas TE. Fracture strength and damage progression of the fiber/matrix interfaces in titanium-based MMCs with different interfacial layers. Composites Part B-Engineering 1998;29:331.

[15] Santulli C. Post-impact damage characterisation on natural fibre reinforced composites using acoustic emission. Ndt \& E International 2001;34:531.

[16] Chen WQ, Lee KY. Three-dimensional exact analysis of angle-ply laminates in cylindrical bending with interfacial damage via state-space method. Compos. Struct. 2004;64:275.

[17] Raghavan P, Ghosh S. A continuum damage mechanics model for unidirectional composites undergoing interfacial debonding. Mech. Mater. 2005;37:955.

[18] Cannmo P, Mahler L, Runesson K. Modelling of interfacial viscoplastic slip coupled to damage in a polycrystalline microstructure. Computational Mechanics 1997;20:12.

[19] Voyiadjis GZ, Park T. Local and interfacial damage analysis of metal matrix composites using the finite element method. Engineering Fracture Mechanics 1997;56:483.

[20] Voyiadjis GZ, Park T. Local and interfacial damage analysis of metal-matrix composites. International Journal of Engineering Science 1995;33:1595.

[21] Lemaitre J, Desmorat R. Engineering damage mechanics Ductile, Creeep, Fatique and Brittle failures: Springer, 2005.

[22] Ananth CR, Voleti SR, Chandra N. Effect of fiber fracture and interfacial debonding on the evolution of damage in metal matrix composites. Composites Part a-Applied Science and Manufacturing 1998;29:1203.

[23] Benabou L, Benseddiq N, Nait-Abdelaziz M. Comparative analysis of damage at interfaces of composites. Composites: Part B 2002;33:215.

[24] Hachemi A, Weichert D. On the problem of interfacial damage in fibre-reinforced composites under variable loads. Mechanics Research Communications 2005;32:15.

[25] Rjafiallah S, Guessasma S. Three-phase model and digital image correlation to assess the interphase effect on the elasticity of carbohdyrate polymer-based composites reinforced with glass silica beads. Carbohydrate Polymers 2011;83:246.

[26] Guessasma S, Benseddiq N, Lourdin D. Effective Young's modulus of biopolymer composites with imperfect interface. International Journal of Solids and Structures 2010;47:2436.

[27] Park JM, Kim DS, Kim SR. Improvement of interfacial adhesion and nondestructive damage evaluation for plasma-treated PBO and Kevlar fibers/epoxy composites using micromechanical techniques and surface wettability. Journal of Colloid and Interface Science $2003 ; 264: 431$.

[28] Guessasma S, Hamdi A, Lourdin D. Linear modelling of biopolymer systems and related mechanical properties. Carbohydrate Polymers 2009;76:381.

[29] Bassir H, Guessasma S, Boubakar L. Hybrid computational strategy based on ANN and GAPS: Application for identification of a non-linear model of composite material. Journal of Composite Structures 2009;88:262. 


\section{Figure captions}

Figure 1. (a) Typical optical micrograph showing bundles of hemp fibres. (b) Magnified view revealing the surface topography of hemp fibres using SEM (c) Experimental set-up for the evaluation of interfacial damage in a starchy composite reinforced using a single hemp fibre. Figure 2. Illustration of the Finite Element model.

Figure 3. Damage growth in a starchy composite reinforced by hemp fibres.

Figure 4. (a) Comparison between mechanical responses associated to perfect, undamaged and damaged composites. Also is illustrated the damage variable ( $\delta$ ) evolution. (b) Principal stress $S_{1}$ counterplots showing the evolution of the structure for different strain levels $(\delta)$. Also are shown the damage variable D as function of deformation. On the bottom-left side is depicted a real damaged structure. Stress levels are given in reduced units.

Figure 5. Effect of fibre geometry on the mechanical response of the damageable starchy composite (a) fibre size, (b) fibre orientation.

Figure 6. Effect of damage criteria on the mechanical response and damage evolution. (a) interfacial strength and shearing constant. (b) Ultimate properties related to the damage variables. (c) Interface stiffness and matrix-fibre contrast.

Figure 7. (a) Identification of the damage related parameters corresponding to the observed mechanical behaviour. Here $\mathrm{EN}=\mathrm{ET}$, where $\mathrm{EN}$ is given in a reduced form, $\mathrm{R}$ is in $\mathrm{MPa}$ and $\beta=0.5$. (b) Correlation between interfacial strength and stiffness in presence of damagedependent behaviour. 


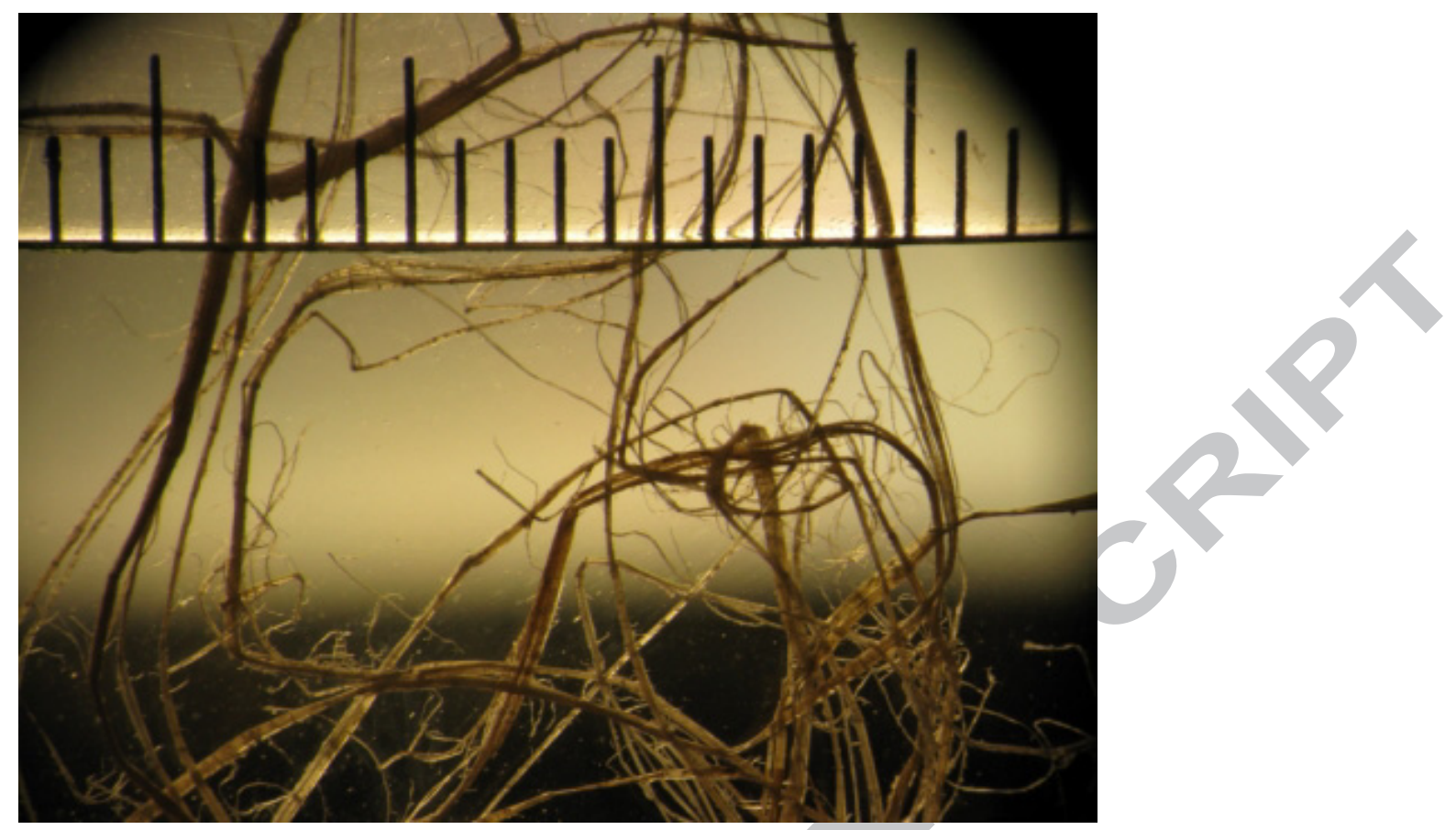

(a)

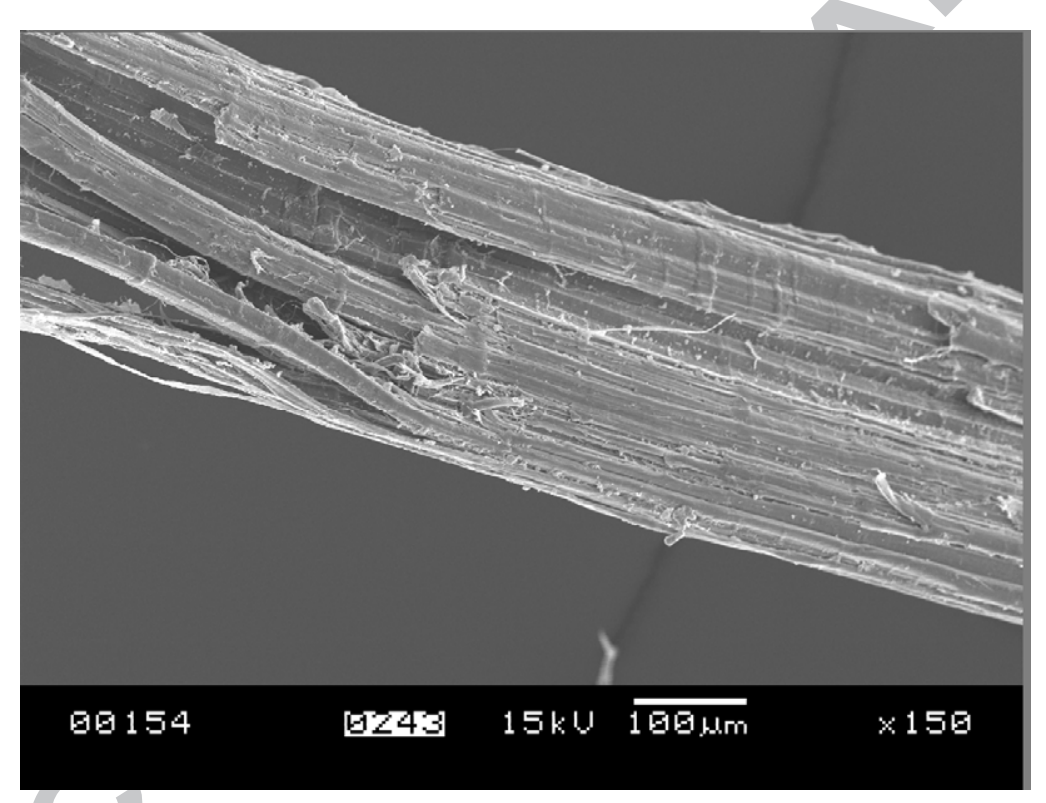

(b) 


\section{ACCEPTED MANUSCRIPT}

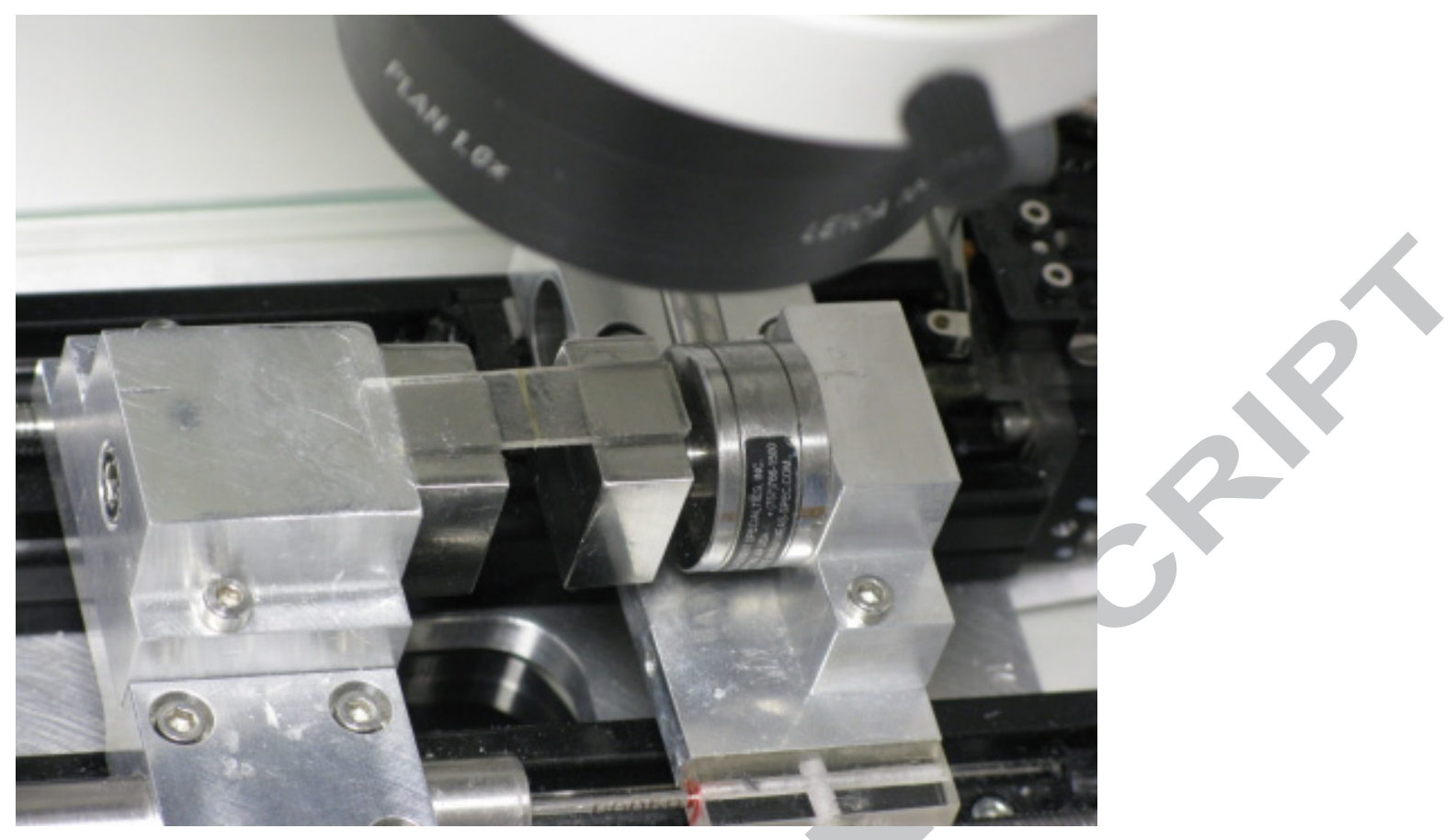

(c)

Figure 1.

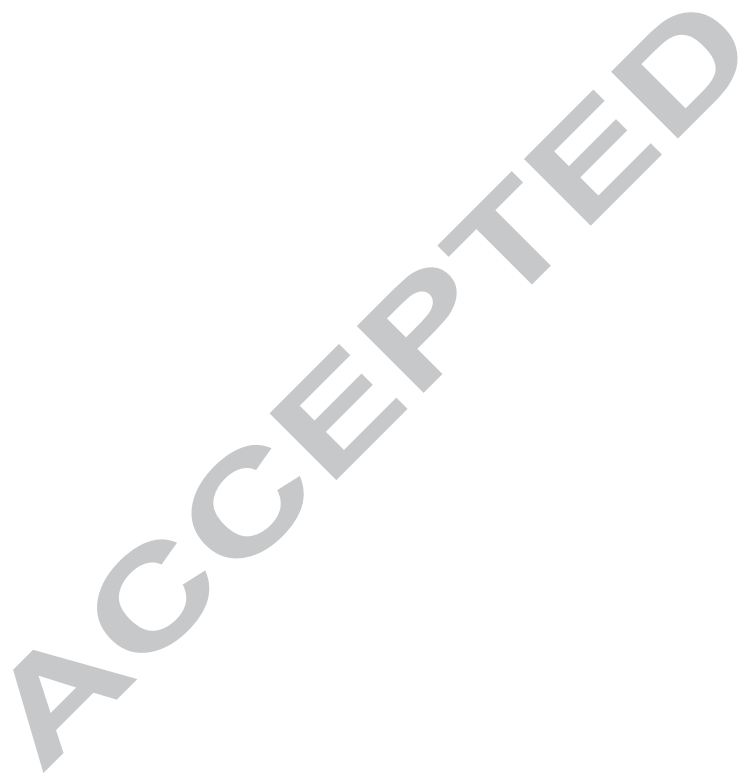




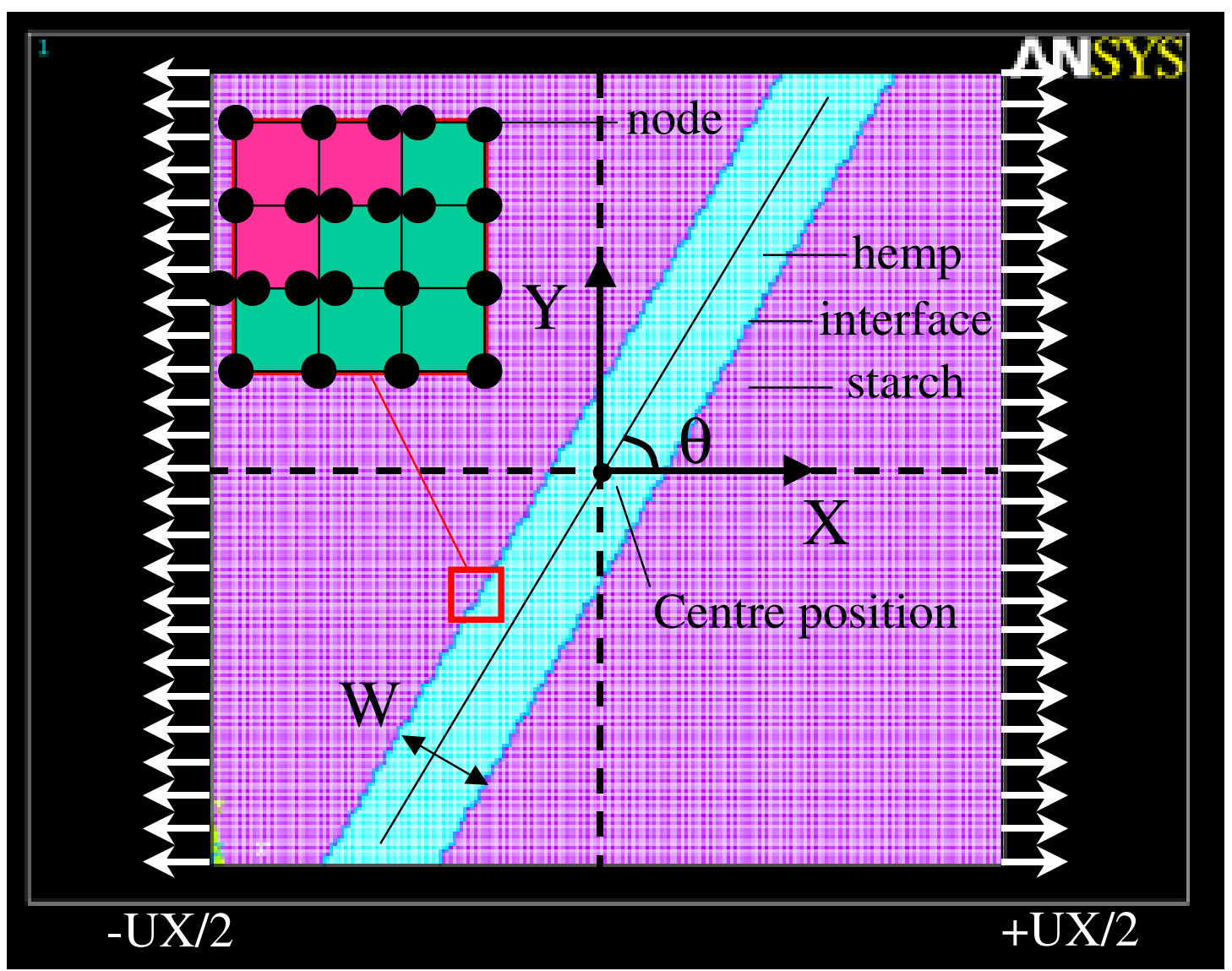

Figure 2. 


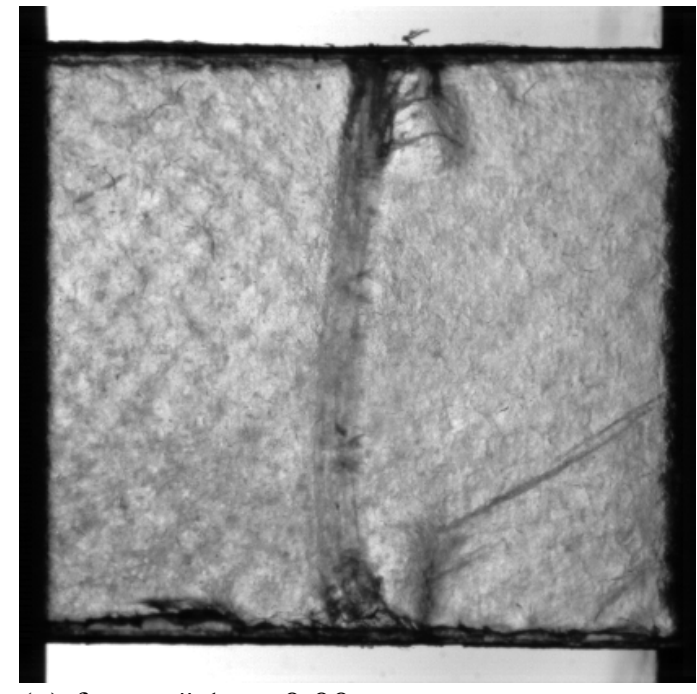

(a) frame \# 1, e=0.00

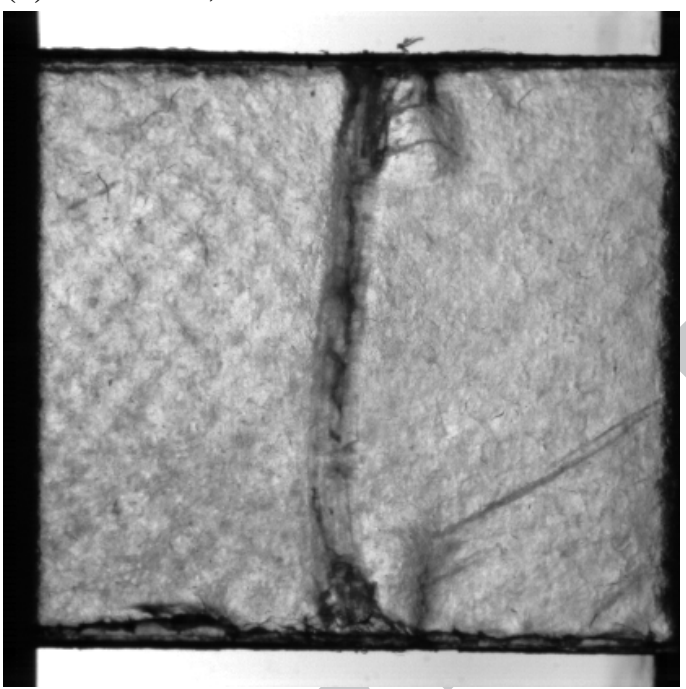

(c) frame \# 1239, e=0.05

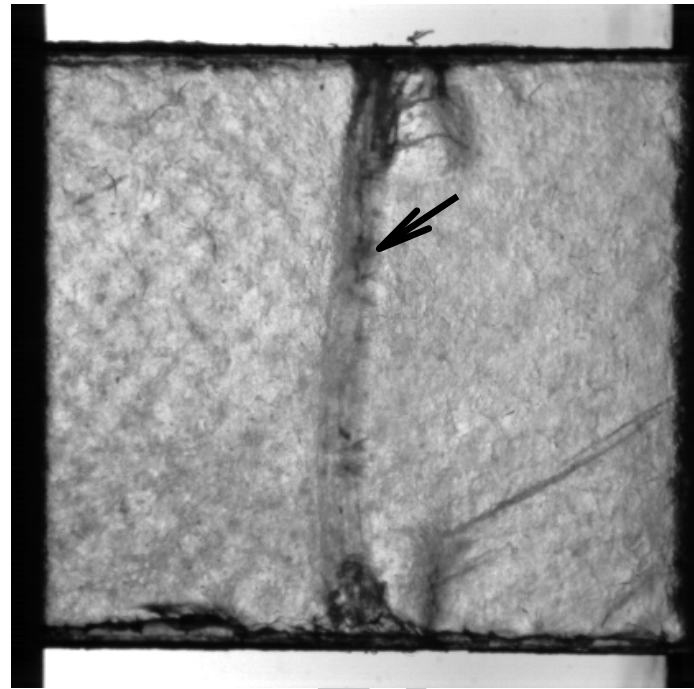

(b) frame \# 991, e=0.04

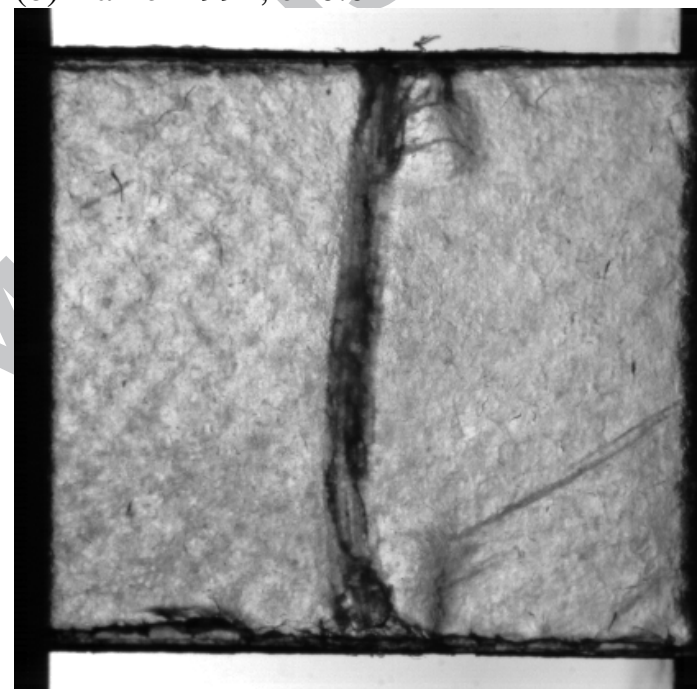

(d) frame \# 1486, e=0.06
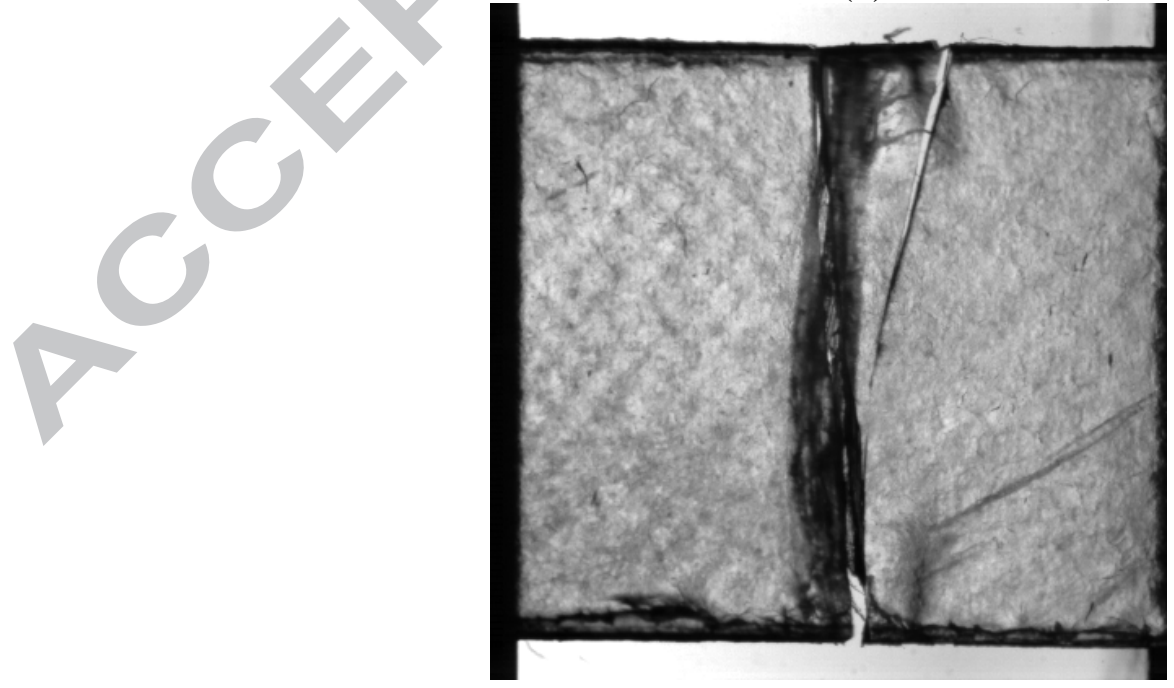

(e) Frame $\# 1531$, e=0.066, failure

Figure 3. 


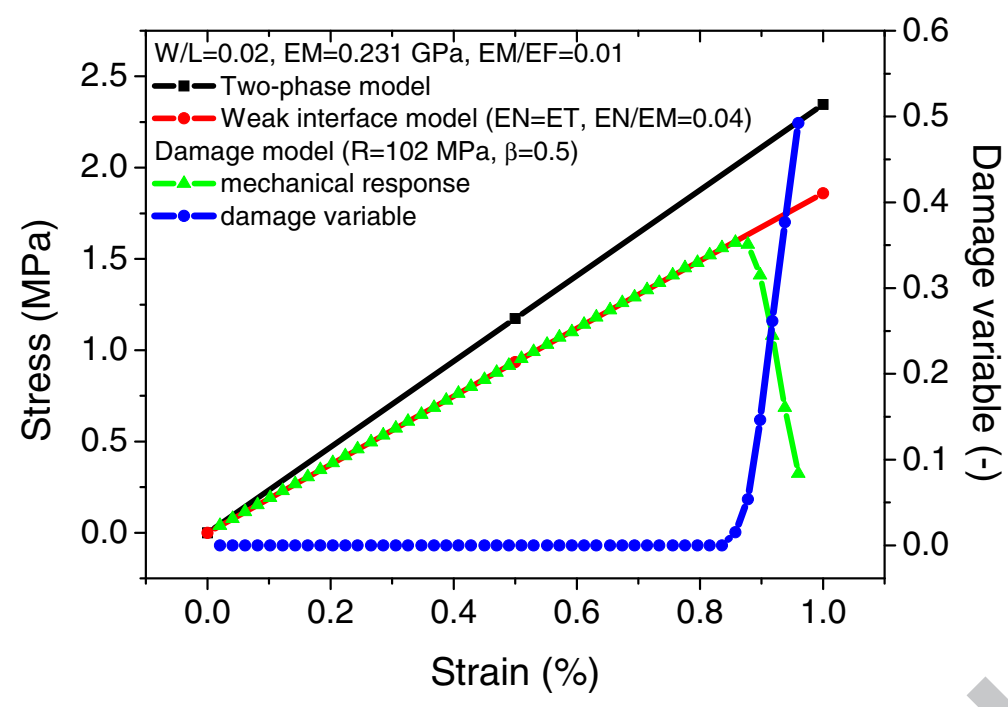

(a)

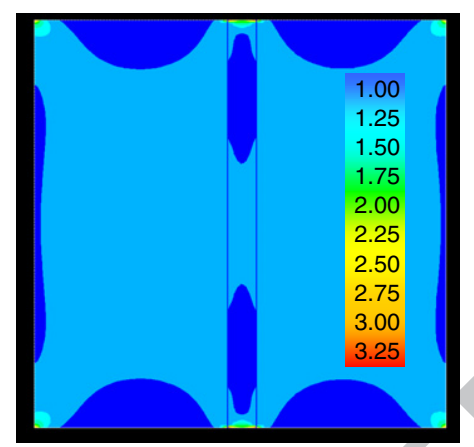

$\varepsilon=0.82 \%, \delta=0.0$

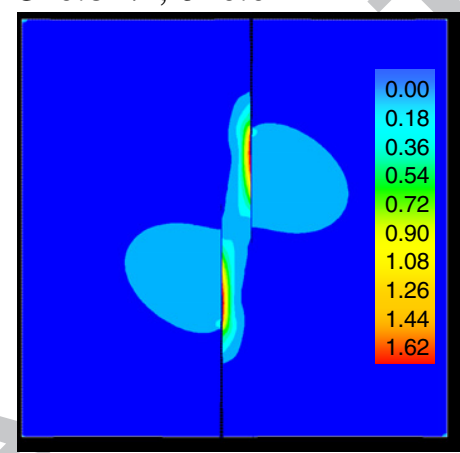

$\varepsilon=0.92 \%, \delta=0.26$

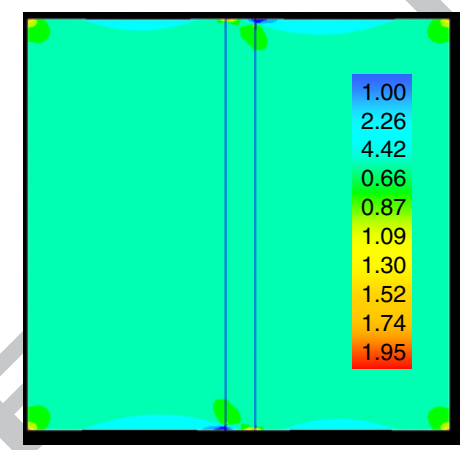

$\varepsilon=0.86 \%, \delta=0.02$

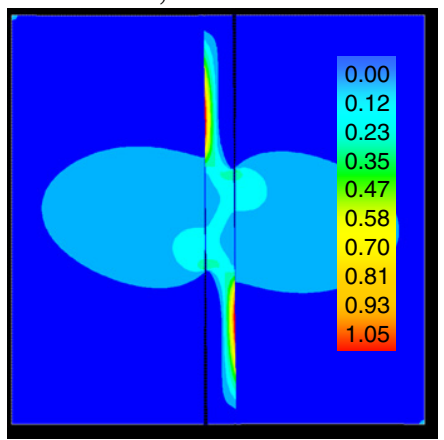

$\varepsilon=1.02 \%, \delta=0.58$

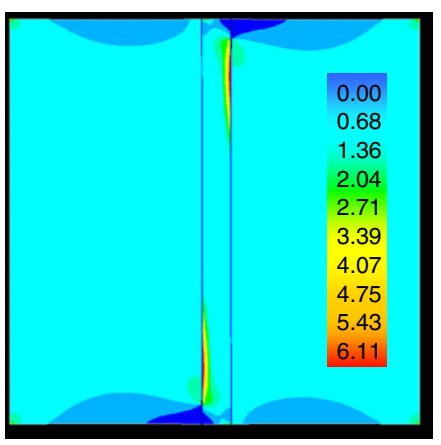

$\varepsilon=0.88 \%, \delta=0.05$

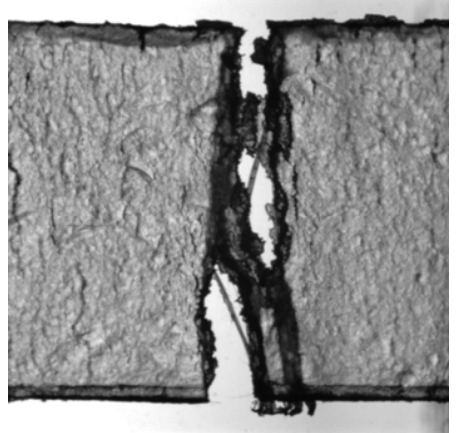

damaged structure

(b)

Figure 4. 


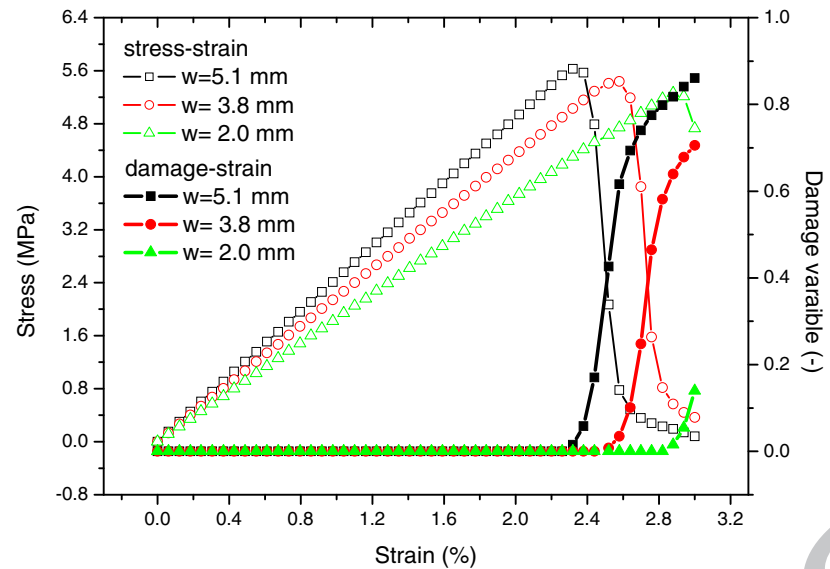

(a)

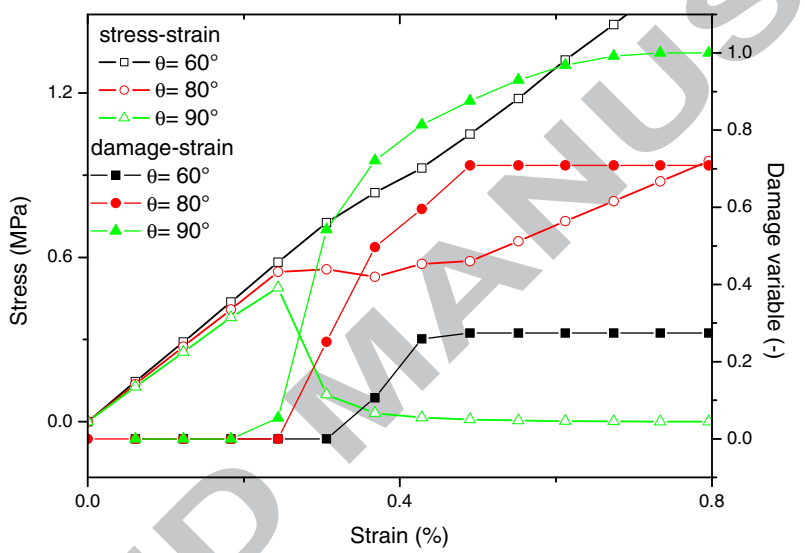

(b)

Figure 5. 


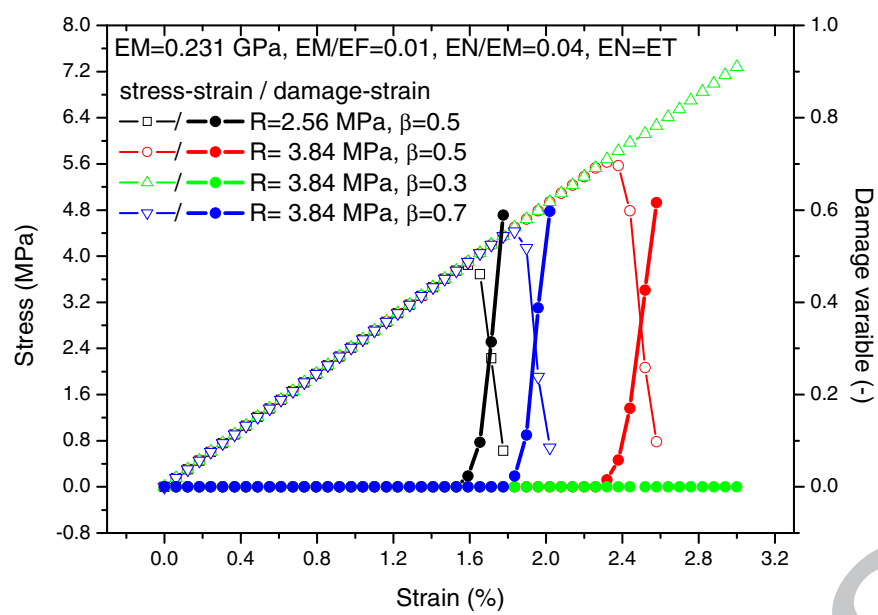

(a)

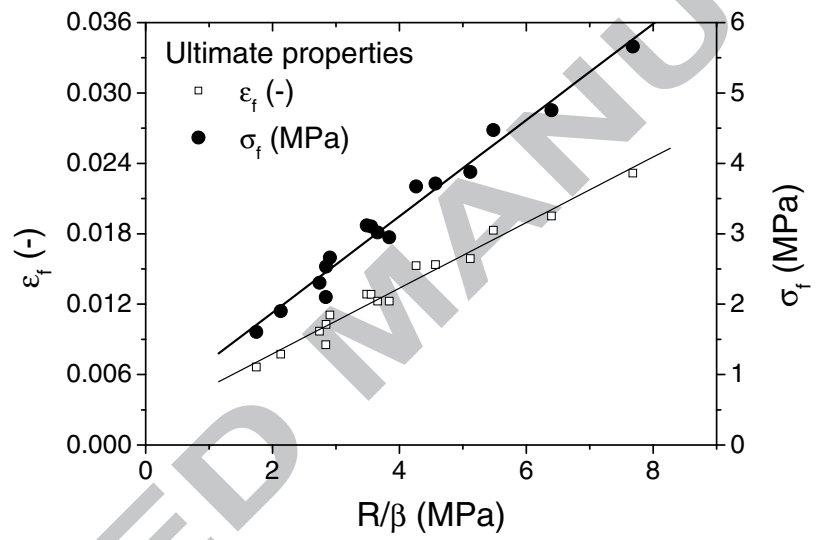

(b)

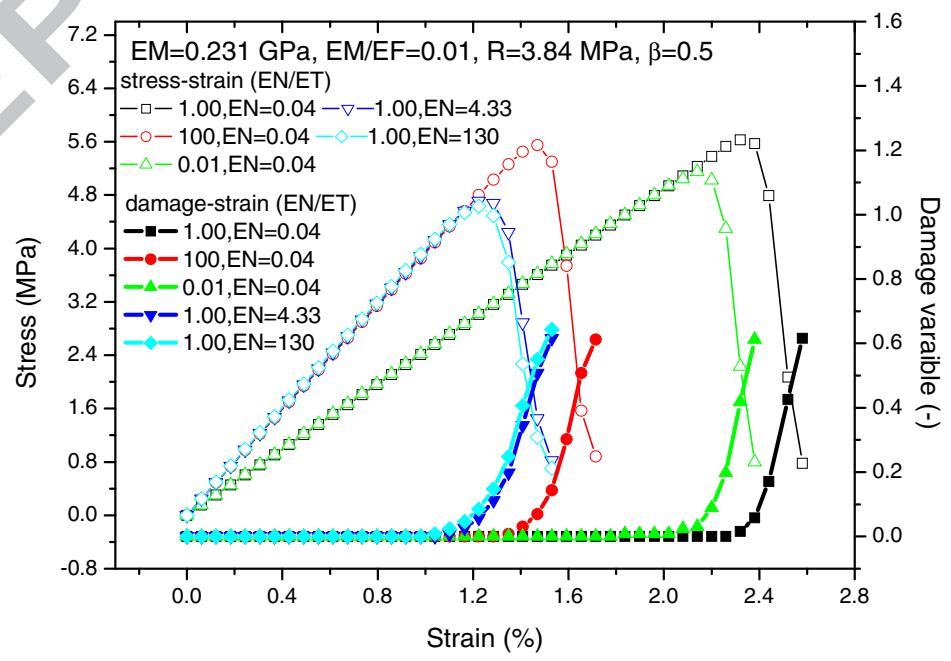

(c)

Figure 6. 


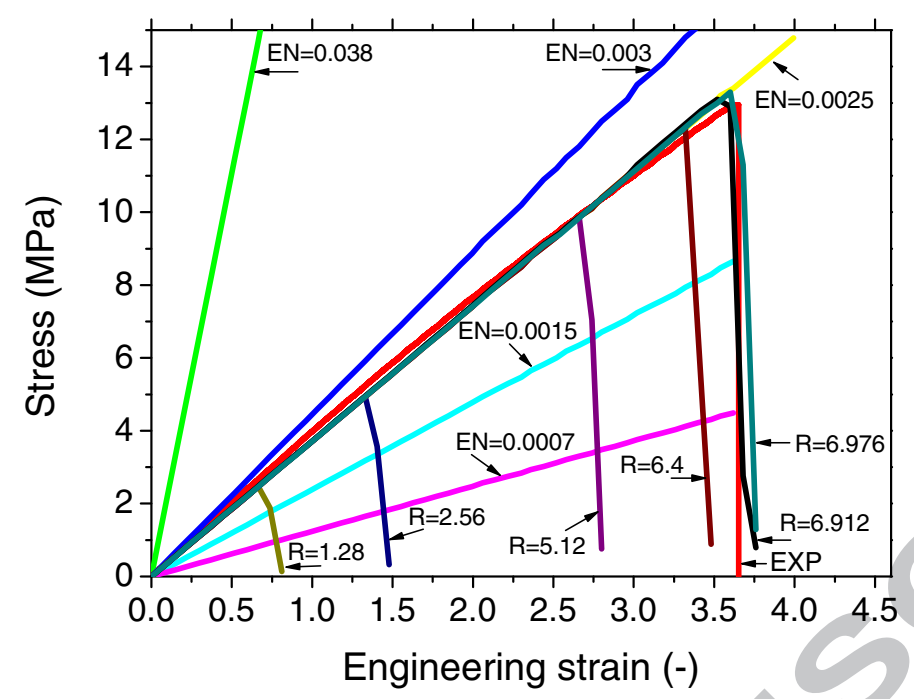

(a)

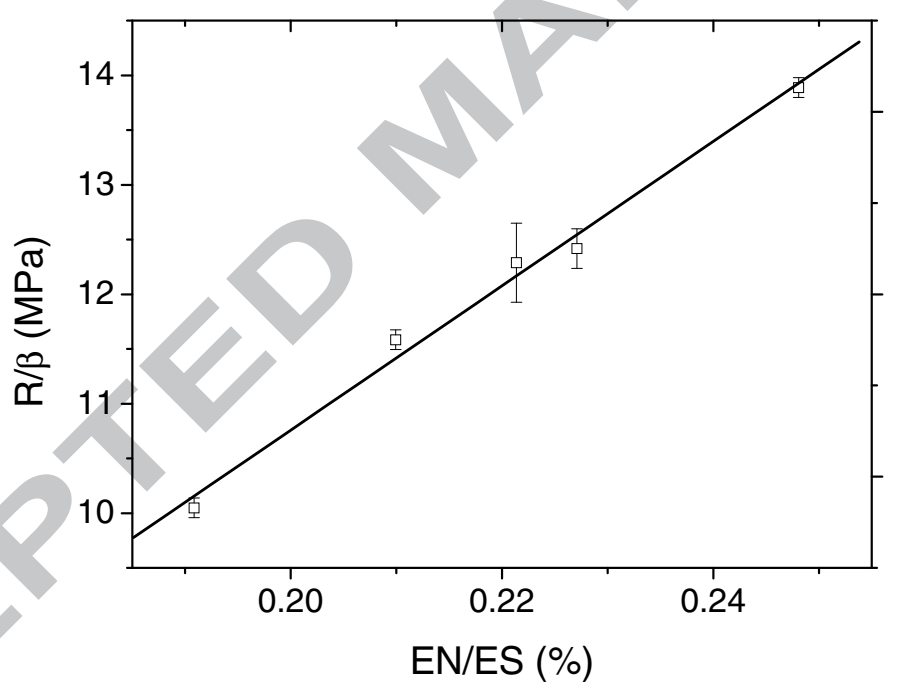

(b)

Figure 7. 


\section{Highlights}

we examine interfacial damage in starch-hemp composites $>$ micromechanical testing reveals failure driven by interfacial damage growth -> FE results show linear dependence of ultimate properties on Coulomb damage criteria $->$ tensile loading leads to largest sensitivity on normal interface stiffness -> Coulomb damage criterion fits the overall behaviour under weak interface conditions 